\title{
Ana C. biografias ficcionalizadas pelas sendas do insólito*
}

\section{Ana C. fictionalized biographies through the uncanny literature}

\author{
Fernanda Lázara Oliveira Santos ${ }^{1}$
}

Recebido em: 07/08/2020

Aprovado em: 15/12/2020

Publicado em: 20/12/2020

RESUMO: Este trabalho empreende reflexões acerca de uma produção contemporânea da literatura brasileira, a partir do conto "Ana C.", que compõe o livro de contos Vésperas (2002) da escritora catarinense Adriana Lunardi. Investiga, sobretudo, em que medida o projeto estético do referido texto concorre para dar visibilidade a importantes escritoras da produção literária contemporânea de autoria feminina, em especial pela vertente do insólito, bem como resgatar nomes de autoras de contextos anteriores, como Ana Cristina Cesar - poeta carioca que possui notoriedade entre os principais nomes da geração mimeógrafo. Metodologicamente, nos aportaremos nos conceitos desenvolvidos por Tzvetan Todorov acerca da literatura fantástica, bem como em outros teóricos da pós-modernidade que discorrem sobre temáticas como a morte e ocorrências do insólito na literatura.

Palavras-chave: Literatura de autoria feminina; Adriana Lunardi; Insólito.

\begin{abstract}
The following article presents an analysis of a contemporary female authorship literature work, "Ana C.", published in a short story compilation entitled Vésperas (2002), written in Portuguese by the Brazilian author Adriana Lunardi. This article investigates how the aesthetic project of this short story is developed to highlight the body of work some important contemporary female writers (mainly throughout an uncanny perspective in Literature) and to revisit some female authors from different historical contexts, such as Ana Cristina Cesar, a poet that was born in Rio de Janeiro and is well known as one of the outstanding writers from her generation (that is called Mimeograph Generation). Methodologically, this article is based on the Tzvetan Todorov's theory about the Fantastic in Literature, and others postmodern scholars that study the death and its occurrences in the Uncanny Literature.
\end{abstract}

Key-words: Uncanny Literature; Female Authorship Literature; Adriana Lunardi.

1. Doutoranda no Programa de Pós-graduação em Estudos da Linguagem pela Universidade Federal de Goiás - Regional Catalão. Graduada em Letras. Pós-graduada em Leitura e Ensino e mestre em Estudos da Linguagem pela Universidade Federal de Goiás - Regional Catalão. Atualmente, exerce docência na área de Língua Portuguesa e Literatura no Ensino Médio.ORCID: 0000-0003-0740-9303 E-mail: fernandalos@gmail.com

\footnotetext{
* Este trabalho é parte dos resultados da pesquisa em desenvolvimento junto ao Programa de Pós-Graduação em Estudos da Linguagem, UFG-RC, nível doutorado, cuja proposta é analisar a prosa literária da escritora catarinense Adriana Lunardi.
} 
SANTOS, F.L.O.

\section{INTRODUÇÃO}

\section{Algumas considerações sobre literatura}

O universo literário com seus contos, romances e tantas outras formas de narração tem se mostrado, há séculos, importante substrato para a experimentação da vida por meio da ficção. A literatura configura-se como uma categoria fundamental para a compreensão do mundo e dos processos de formação de identidades. Mesmo diante da capacidade imperecível da arte literária, observando-se os movimentos ocorridos no terreno da crítica literária contemporânea, é possível depararmo-nos com rumores sobre a extinção da ficção em prosa. Entretanto, a continuidade na publicação de vários gêneros de narrativa é um fato, o que ratifica, assim, a afirmação da arte literária. Nos mais diferentes formatos e subgêneros, as narrativas se fazem presentes, mantendo vivo o ato de ler, mesmo com a hegemonia audiovisual. Além de fomentar o deleite intelectual, a literatura permanece essencial como instância de representação e crítica da realidade, possibilitando o trânsito intersubjetivo de significados.

Considerando-se as movimentações da literatura produzida no Brasil nas últimas décadas, observamos a existência de uma intersecção entre o que se produz e o meio onde se produz - classe social, etnia, gênero e demais elementos que nos levam a pensar a importância do lugar de fala das vozes que se manifestam através da escrita. Mais que apreciar um projeto estético, precisamos considerar a relevância de conhecer quais são os autores e autoras e como eles vêm construindo as representações no âmbito das produções literárias brasileiras contemporâneas. Ao percorrer o caminho dessas investigações, observamos a ascendência do protagonismo das mulheres, seja por meio das representações empreendidas pela autoria feminina, fazendo emergir os deslocamentos da mulher que se coloca ante espaços de opressão de modo a problematizar o universo literário, seja pela constituição de personagens alternativas às visões dominantes.

Quanto à incursão das mulheres no campo literário, cabe salientar que a figura da autora, historicamente, foi deformada por silenciamentos e interrupções (TELLES, 1992). É possível observarmos a tradição imperativa do patriarcado que relegou a legitimidade cultural feminina compondo um cenário desestimulante para que mulheres escrevessem ficção, dadas as proporções assimétricas dos papeis sociais bastante distintos reservados ao masculino e ao feminino. Em movimentos contrários a essa deformidade a que se refere Telles, temos na contemporaneidade o crescimento exponencial de encadeamentos e 
SANTOS, F.L.O.

obras que vão, aos poucos, extinguindo os alheamentos e desatenções antes apontados para a literatura de autoria feminina.

Para além da forma, a arte literária é um projeto de conteúdo político e social, que entrelaça campos de significados e sentidos, portanto, assinar uma obra de ficção cujos valores sejam reconhecidos foi, e ainda pode ser, um dos grandes desafios das mulheres. Diante disso é que voltamos nosso olhar para o cenário da contemporaneidade, mais especificamente para a produção de autoria feminina de Adriana Lunardi (1964).

Escritora de obras literárias que compõem um consistente projeto estético, Adriana Lunardi apresenta-se, no cenário da literatura brasileira contemporânea, filiada a uma tradição que busca através de sua tessitura a compreensão do fenômeno humano, abrangendo, no âmbito deste caminho, sendas que perpassam por temas como a vida e morte e, sobretudo, sobre a transcendência advinda da arte literária.

De escritora de documentários para a TV a autora de romances e contos, Adriana Lunardi assina obras literárias que tiveram excelente acolhida em países como França, Portugal, Croácia e Argentina. Seu primeiro livro, As Meninas da Torre Helsinque (1996), recebeu prêmios importantes como o Fumproarte e o prêmio Açoriano de Literatura (1997) nas categorias de autorrevelação e melhor livro de contos. Quando do lançamento de Vésperas (2002), recebeu indicação para o prêmio Jabuti. Corpo Estranho, romance publicado em 2007, foi indicado ao Bourbon de Literatura. Em 2014, com a publicação de A longa estrada dos ossos, recebeu o Prêmio lcatu de Artes.

A produção lunardiana sustenta a reflexão sobre momentos definidores da existência humana com especial atenção à vida das mulheres, sobretudo daquelas que atuaram no campo das artes literárias. Em entrevista concedida ao programa Entrelinhas (2009) da TV Cultura, Lunardi reflete sobre como a arte torna perenes seus autores cujas produções tornam-se incólumes ao tempo: "Esse aparente momento em que a gente se vê diante de um limite existencial, limite vital, na verdade, que nos é imposto como espécie, é uma forma de superação. Nossa eternidade é a arte". Reconhecer-se como intelectual, artista e produzir seus textos sobre a escrita de outras mulheres que se destacaram na literatura propicia a legitimação da experiência das mulheres e suas expressões artísticas e intelectuais, bem como sua existência e sua importância. Isso porque, conforme sabemos, por um sem-número de vezes, questionou-se a capacidade das mulheres enquanto escritoras de uma literatura de qualidade ou ainda, atribuiu-se àquelas que se demonstravam subversivas às barreiras de seus lares, o rótulo de histéricas.

Historicamente, observamos a tradição imperativa do patriarcado que relegou a legitimidade cultural feminina compondo um cenário desestimulante para que mulheres

Revista do SELL, Uberaba/MG (online) - V. 9 n. 2, p. 387-401, jul./dez. - 2020. 
SANTOS, F.L.O.

escrevessem ficção. A escritora e psicanalista Regina Navarro Lins (2016) observa que o século XIX foi palco de expressivas manifestações falocêntricas. Segundo Lins, esse comportamento fica evidente em declarações de poetas e filósofos como Augusto Comte, que viu a feminilidade como uma espécie de infância prolongada e Balzac, que achou que as mulheres eram incapazes de raciocinar ou de absorver conhecimento útil. Na década de 1920, Virginia Wolf, cujo nome já era notável, ao discorrer sobre as mulheres e a ficção, nos convida a pensar de maneira lancinante em que medida o lugar destinado à mulher na sociedade acarretou (e talvez ainda o faça) dificuldades para dar visibilidade à sua produção. Em Um teto todo seu (2014), Woolf diz das condições básicas para que uma mulher escreva ficção, ressaltando a necessidade de que as mulheres dispusessem de um espaço singular para se dedicarem à escrita sem interrupções e sem alheamentos.

A voz lunardiana tem reverberado no cenário da literatura brasileira contemporânea através de sua prosa literária, tecida no espaço ficcional em que ocorrem movimentações vigorosas e criativas. Claramente influenciada por célebres escritoras da literatura universal, Adriana Lunardi intertextualiza e compõe seu processo de criação quase que num gesto de antropofagia, movimento comum nas escritoras, sobretudo a partir da segunda metade do século $X X$ até a contemporaneidade.

Sua prosa revela um tom bem demarcado de exaltação e fascinação pelo literário, e uma forte presença dialógica com figuras culturais determinantes que propiciam a legitimação de seu relacionamento com a literatura, o que parece ser o eixo central de sua tessitura. Sua forma de narrar aponta para traços de autorreferencialidade e metaficção estéticas que sugerem o uso do texto literário como espaço de afirmação da autenticidade da autoria feminina.

No conto eleito para esta análise, Lunardi trilha pelas sendas do insólito, do fantástico. Seu fazer literário, tecido sob os signos da intertextualidade, remonta a trajetória de aspectos da vida pessoal e artística de renomadas escritoras, evidenciando o tema da morte e, mais especificamente, dos momentos finais, da transposição da fronteira entre o mundo dos vivos e dos mortos, num jogo lúdico entre realidade e ficção. Este é o mote sobre o qual pretendemos incidir luz neste trabalho, observando em "Ana C." como Adriana Lunardi aborda o entrelaçamento das trajetórias de um indivíduo à beira da morte, cujas referências biográficas indicam Caio Fernando Abreu e Ana Cristina César, nome expoente da geração mimeógrafo ${ }^{1}$.

\footnotetext{
${ }^{1}$ A geração mimeógrafo foi o movimento ocorrido na literatura brasileira na década de 1970 que sucedeu a Tropicália. A denominação do movimento resulta da busca de intelectuais e artistas de todo o país por meios alternativos da difusão cultural, sendo o mimeógrafo a ferramenta tecnológica mais acessível e usada no período para a propagação dos escritos. Editoras de renome daquele cenário não aceitaram a produção literária assinada por aqueles que se inscreviam neste
} 
Nos limites deste texto, nos ateremos especialmente à aparição do espectro de Ana C. que, no conto em análise, vem conduzir o narrador-personagem para o mundo dos mortos. Este é o momento de transgressão da realidade responsável por elucidar o caráter insólito da narrativa que, ao desenvolver-se, vai delineado os momentos de uma aparição fantasmagórica em clima onírico e enigmático. Embora o enredo do conto trate da transposição do mundo terreno para o mundo dos mortos, há uma sutileza na construção das cenas tal que, não fossem pelo estranhamento e hesitação causados pela aparição de um espírito, o leitor incauto ver-se-ia diante da descrição de uma cena muito mais delirante que grotesca, já que se trata da semiconsciência do narrador-personagem cuja vida vai se findando.

A busca pela compreensão da passagem da vida para a morte suscita formas simbológicas de representação desde o despontar da humanidade. Essa curiosidade está manifesta já em textos predecessores, conforme representa a mitologia grega, em que narrativas descrevem lugares como o reino Hades, lugar onde habitariam as almas daqueles que já não mais pertenciam ao mundo dos vivos. Em Odisseia ${ }^{2}$ (séc. VIII A. C.) de Homero, o canto XI menciona a descida de Odisseu ao Hades à procura de Tirésias, evidenciando a crença dos antigos ocidentais na imortalidade da alma.

-- Divino filho de Laertes, Odisseu astucioso, por que você, ó infeliz, deixou a luz do sol para vir a este triste lugar? [...] Tirésias, depois de dizer isso, partiu rumo à morada de Hades. (VASCONCELLOS, 2019, p. 53).

A crença na vida pós-morte é evidenciada também pela figura mitológica de Caronte, o barqueiro do inferno, responsável por atravessar os recém-mortos para o submundo das almas. Cite-se aqui o costume dos gregos antigos de enterrar seus cadáveres com uma moeda na boca para pagarem ao barqueiro pela travessia dos rios Estige e Aqueronte.

Em "Ana C." é de uma mulher a aparição espectral que vem conduzir o narradorpersonagem para o mundo dos mortos, recriado, conforme se observa, a exemplo da mitologia grega. Dedicado ao estudo dos vivos e dos mortos na sociedade medieval, o pesquisador Jean-Claud Schmitt (1999) revela-nos como os defuntos podem ser úteis aos vivos, podendo oferecer conselhos úteis e anunciar-Ihes a morte iminente. Desta feita, "na

movimento. Estando então à margem do circuito editorial, o que foi produzido pela literatura deste contexto recebeu o rótulo de poesia marginal, por não circular em galerias tradicionais e não serem reproduzidas por outros meios de fotocópia. Conhecida por produzir uma literatura marginalizada, escritoras como Ana Cristina Cesar fizeram de seus escritos um veículo para a crítica feminista por meio de temáticas e assuntos pouco convencionais, merecendo lugar de destaque ainda na contemporaneidade conforme se observa na obra em análise.

${ }^{2}$ Atribuem-se ao poeta grego Homero dois longos poemas épicos, a llíada e a Odisseia. Embora não se possa afirmar seguramente que de fato Homero é o autor de tais epopeias, não há registros do contrário. A edição a que fazemos referência neste texto trata-se da adaptação de Paulo Sérgio de Vasconcellos (2019). 
SANTOS, F.L.O.

sociedade cristã um morto não pode prestar maior serviço a um vivo do que o convidando a preparar-se para morrer" (SCHMITT, 1999, p. 93). Conforme veremos, essa é a função que o espectro da escritora Ana C. vem cumprir no conto em questão. É também sobre este ponto que incide o foco de nosso maior interesse nesta análise: evidenciar o que denominamos como um caráter insólito do texto selecionado para esta apreciação. Tornemos claro, contudo, que para efeito de análise, elegemos, dentre as várias nuances de significação para o insólito, a que o define como aquilo que é incomum, extraordinário, que causa estranhamento e é contrário às regras comuns, pois,

o leque das vertentes do insólito ficcional é amplo, abarcando uma diversidade significativa de manifestações estéticas em que o trabalho ficcional é sustentado pela emergência de situações insólitas e que geralmente colocam o leitor em contato com o desconhecido, o inexplicável. Assim, pode-se sugerir a manifestação do insólito ficcional sempre que elementos de qualquer uma das categorias da narrativa - tempo, espaço, personagem ou ação - provoquem, nos seres da ficção - narrador, narratário, personagem - e/ou nos seres da realidade - leitor virtual e empírico - um incômodo. (GARCIA, VOLOBUEF, KHALIL, 2011).

Distanciando-nos de explorar com mais minúcia as definições que envolvem o termo, pretendemos apenas elucidar alguns pontos que nos permitem experienciar o insólito através da escrita lunardiana e da construção de seus personagens com especial destaque ao momento em que a narrativa nos apresenta o espectro e a reação do narradorpersonagem diante dessa situação insólita.

\section{"Ana C."}

O nome que intitula o conto em análise diz respeito à escritora carioca Ana Cristina Cruz Cesar (1952-1983). A poetisa que se despediu da vida prematuramente aos 31 anos torna-se inspiração para a composição lunardiana que se serve das biografias de Ana Cesar e do escritor gaúcho Caio Fernando Abreu (1948-1996) para dar corpo ao seu enredo. Mais que um título, Ana $\mathrm{C}$. representa a assinatura da jovem escritora que se deu a conhecer por desviar-se do contínuo em seu estilo poético.

A fabulação de "Ana C." constitui-se a partir dos momentos finais da vida do narrador-personagem do conto, para quem a pesquisa de Vera Lopes Silva (2018) aponta ser Caio Fernando Abreu. A partir de estudos biográficos, a pesquisadora afirma ser factível a amizade entre Caio e Ana, que aparece embaralhada pela ficção neste conto. Seria possível comprovar tal relação observando-se documentos,

"como o que se lê na carta em que Ivan Matos, amigo de Caio, relata a Paula Dip: 'Ele [Caio] ficou muito abalado com o suicídio da Ana C. porque eles estavam meio brigados na época e a sensação dele era de remorso por não ter reatado plenamente com ela antes'” (SILVA, 2018, p. 302).

Revista do SELL, Uberaba/MG (online) - V. 9 n. 2, p. 387-401, jul./dez. - 2020. 
Segundo observa Carlos André Ferreira (2010), Caio Fernando Abreu fez da arte literária um caminho para dizer do sujeito que se vê deslocado no mundo contemporâneo. Acometido pela Aids e sensibilizado pelas marcas estigmatizadas da doença, deixou em sua obra marcas da solidão, aspectos de sua afetividade e a enfermidade que vivenciou. A síndrome sofrida por Caio está presente de maneira velada, lida nas entrelinhas daquele que se via sob a condição de ser soropositivo. O material biográfico sobre Caio Fernando Abreu é a fonte na qual bebe Adriana Lunardi para recriar, em caráter ficcional, os instantes em que o escritor vê-se sendo vencido pela doença. Talhando as impressões do narradorpersonagem com cuidado artesanal, a contista coloca o leitor a par do estado em que se encontra o enfermo, servindo-se do conhecimento fatual de suas personagens para revisitálos e produzir a quimera.

As impressões da enfermidade de Caio vão sendo evidenciadas desde o princípio na narrativa. As queixas de noites mal dormidas, a tosse, a companhia da enfermeira, as recorrentes idas ao hospital, tudo isso narrado junto ao emaranhado de sensações e impressões que vão sendo descritas concomitantemente às experiências de leitura realizadas pelo narrador. "A lâmpada de cabeceira permanece acesa, e entre os acessos de tosse eu podia retomar a leitura de Alice no país das maravilhas" (LUNARDI, 2002, p. 41). A obra de Lewis Carroll citada no conto parece ser emblemática para a situação vivida pelo personagem. As confusões e oscilações entre realidade e fantasia oriundas do estado de saúde do moribundo o fazem deslocar entre o estado de delírio e consciência tornandose análogas às aventuras vividas por Alice em suas aventuras surreais. Novas referências literárias vão sendo construídas na medida em que surgem também outras oscilações no estado de consciência do narrador, que se encontra no hospital:

Homens fortes encaixam a maca nos trilhos e sou deslizado para dentro daquela grande barriga, em uma espécie de nascimento ao contrário. Quero voltar ao útero de minha mãe, ouço Ginsberg uivar, do lado de fora. O aro de tartaruga de seus óculos desaparece atrás da cortina de uniformes que se fecha sobre mim. [...] Agora o monóculo é de Machado e, assim, parece que estou indo em boa companhia. (LUNARDI, 2002, p. 43).

Esse trecho denota a experiência de alguém que conhece ícones da literatura universal, tais como o norte-americano Irwin Allen Ginsberg e o brasileiro Machado de Assis. Até mesmo o nome do animal de estimação mencionado no conto parece ter sido escolhido propositadamente para reforçar a ideia de ligação com o universo literário. A gata Zelda, cujo nome remete à memória da escritora estadunidense Zelda Fitzgerald, é mencionada como sendo uma fiel companheira do personagem. "Zelda não está por ali. Gatos nunca se 
SANTOS, F.L.O.

despedem. Poupam-nos de nossas próprias pieguices e, solenes, nos ensinam a também falsear dignidade" (LUNARDI, 2002, p. 43).

Todo o desenvolvimento da narrativa vai conduzindo o leitor para um universo onírico e, ao mesmo tempo, denotando a debilidade do personagem que pressagia o próprio fim. "São tantos os suores, que preciso ser mudado muitas vezes. [...] Volto a ser um menino incapaz de administrar a si mesmo. Estou leve como os meninos magros que se negam a comer [...]" (LUNARDI, 2002, p. 44). Ainda diante do quadro de abatimento, as referências à leitura continuam sendo explicitadas, evidenciando mais uma vez que a ficção fora construída a partir de dados biográficos de um personagem leitor, conhecedor e apreciador da arte literária. "Ela se lembrou de trazer o livro que eu estava lendo e sinto infiltrar-se em meus ossos uma gratidão beatífica" (LUNARDI, 2002, p. 44). Todas essas referências parecem fazer parte da meticulosa tessitura da autora para propiciar o clímax do conto.

O espaço que vai sendo descrito propicia a inserção do leitor no ambiente em que são maximizadas as agonias do personagem.

O carro arranca e a sirena começa a uivar. [...] Um rápido degrau e sou empurrado para o novo ambiente. [...] Tudo será branco de agora em diante. Os aventais, os lençóis, o interior da ambulância. [...] O velho sétimo andar. A antessala do inferno, cabala das despedidas (LUNARDI, 2002, p. 44-46).

Conforme observa Ozíris Borges Filho (2008), o espaço cumpre a função de, em determinadas cenas, estabelecer uma analogia entre o lugar que a personagem ocupa e o seu sentimento, reforçando assim o clima que anuncia a fragilidade da vida que se esvai. O espaço onde preponderam o medo e a insegurança gerados pela iminência da morte e a oscilação da consciência do personagem configuram o momento da primeira manifestação causadora de hesitação. Narrada com riqueza de detalhes, a cena dá indícios de que uma presença sobrenatural se faz presente.

Um roçar suave envolve minha mão esquerda, como se alguém a acariciasse. Penso em Anita, de quem não ouço a voz, mas imagino próxima, vigilante. Meus dedos tentam responder ao afago e entrelaçam, surpreendentemente, não a carne macia de Anita, mas uns dedos longos e frios como pedras de gelo. Debaixo do lençol, meus ossos reagem. Estremeço. A mão gelada supõe minha hesitação e não insiste (LUNARDI, 20002, p. 47).

A partir daí o leitor passa a acompanhar a travessia do personagem para o mundo dos mortos, evidenciada, sobretudo, pela companhia do fantasma ${ }^{3}$ da escritora Ana C. a

\footnotetext{
${ }^{3}$ Segundo o Dicionário Digital do Insólito Ficcional, a crença no Fantasma ainda nos dias de hoje em determinados círculos, encontra respaldo em decorrência da ancestral e perene angústia do ser humano sobre as dúvidas que cercam sua finitude. Em Língua Portuguesa, "fantasma" foi herdado diretamente da palavra anglo-francesa do século XIV fantosme, cuja raiz se encontra no latim phantasma ("fazer aparecer", "revelar") uma derivação do grego phantázein. Semelhante, então, ao sentido da palavra "monstro", cuja origem se encontra no verbo latino monere ("avisar", "mostrar"), o fantasma se coloca como um aviso sobre algo que foge à normalidade.
}

Revista do SELL, Uberaba/MG (online) - V. 9 n. 2, p. 387-401, jul./dez. - 2020. 
SANTOS, F.L.O.

quem serão feitas referências evidentes posteriormente. Interessante observar que Lunardi utiliza uma composição textual que nos conduz, em vários momentos de sua narrativa, a pensar se essas passagens ocorrem ou se são apenas resultado das oscilações de consciência da personagem em seu estado de quase morte.

A mão agora segura meu ombro. O contato frio já não produz o mesmo desequilíbrio de antes, embora ainda me sinta um barco bêbado que aderna. Espio por uma fresta da pálpebra esquerda e vejo lentes escuras, levemente convexas, investigando se por acaso ainda respiro. Não são os óculos de Ginsberg, desta vez. Há um jeito brincalhão por trás daquela camada de plástico, um jogo de esconde-esconde, de amigo-oculto, na armação quase grande demais para o rosto que aos poucos vou reconhecendo, cheio de dúvidas e inseguranças, mas cada vez mais certo de estar diante do olhar eternamente encoberto de Ana C. (LUNARDI, 2002, p. 49).

A expressão "eternamente encoberto" manifesta a ideia de que aquele olhar estaria para sempre enterrado, sem possibilidade de existência física, pois pertence a uma pessoa que já está morta.

Mais uma vez a construção do espaço contribui para a simbologia advinda dos eventos de morte. O leitor acompanha a descrição do prédio hospitalar em que se encontra o personagem, que descreve com ênfase a frieza do lugar no qual predomina a cor branca. Nas roupas dos médicos e enfermeiros, nos lençóis dos leitos, nas paredes, nas luzes. Essa predominância do branco produz o efeito do não vívido, do frio, do silenciamento interior a que o personagem está acometido. Segundo Jean Chevalier e Alain Gheerbrant (2008), o branco é primitivamente a cor da morte e do luto, pois possui aspecto nefasto, contrastante com o vermelho, por exemplo, que seria a cor símbolo da vivacidade. Seria, pois, o branco, a cor da mortalha, de todos os espectros, de todas as aparições. A simbologia do branco representaria, ainda segundo os autores supracitados, a cor dos primeiros passos da alma como também as almas de outro mundo.

Delineada não somente com a ausência de cores, mas também com a languidez da vida, a cena em que aparece o fantasma de Ana C. vai colocando o leitor diante de uma aparição que transpõe o limiar entre o mundo dos vivos e dos mortos. Essa transposição garante ao personagem que agoniza a segurança de que precisa para fazer a travessia, revelando o fantasma de Ana como uma espécie de guia para o mundo espiritual. Sua aparição recebe destaque inclusive na descrição da aparição que, de tal feita, vai deixando traços de conforto e acolhimento para aquele que se encontra em desamparo.

Uma luz âmbar lambe as paredes, os lençóis e a pele de Ana C. Ela passeia devagar, demorando-se para apreciar cada um dos aparelhos ligados ao meu corpo. De quando em quando, volta para mim seu meio sorriso, segura de ter sob controle a irrealidade desta visão. Quero falar, ensaio algumas frases que ficam grudadas no céu ressecado da boca. Há tanta coisa a ser dita e estou encarcerado em minha própria língua. Ana se aproxima,

Revista do SELL, Uberaba/MG (online) - V. 9 n. 2, p. 387-401, jul./dez. - 2020. 
debruça-se sobre a maca, e encosta o ouvido em minha testa. Abandone o navio das palavras, ouço-a dizer naquela voz levemente embargada, respirando entre sílabas, fazendo de cada fala poesia (LUNARDI, 2002, p. 49).

Ressalte-se que a aparição deste espectro não cumpre a função costumeira de causar medo ou assustar aquele que o presencia. Contrário a isso, embora provoque uma estranheza por ser uma ocorrência que nos interpela, não nos é familiar e tampouco habitual, a aparição suscita no personagem e, consequentemente, no leitor, muito mais aconchego que temor. Sua função parece ser a de quem está designado a guiar o caminho para aquele que se encontra prestes a fazer a travessia para o mundo espiritual e sente-se inseguro.

Ficamos de mãos dadas, contentes com o reencontro. Uma alegria de ácido lisérgico, extasiada, dessas que reorganizam o caos. Tomo um grande gole de ar e respiro sem dor, como se aquele aparato de manter vivo não estivesse ali, censurando minha partida (LUNARDI, 2002, p. 50).

A morte é tratada neste conto como um elemento de transcendência da vida. A contista se encarrega de agregar leveza a esse fenômeno contagiando passagens biográficas com a ficção. Assim, Adriana Lunardi nos apresenta como resultado a perenidade da literatura e de seus autores cujas memórias não sucumbem perante o declínio do corpo físico. Essa mistura entre realidade e ficção é evidenciada informando que a figura de Ana C. se trata de um espectro, já que o episódio de sua morte é referenciado, assegurando que esta figura não pertence mais ao mundo dos vivos.

Quando atendi o telefonema avisando que Ana C. tinha se atirado do sétimo andar, tive a sensação de que aquela notícia já era antiga. No entanto, acabara de acontecer. Mais uma vez o tempo adiantava-se ao espaço, bagunçando a ordem prática que se espera do universo (LUNARDI, 2002, p. 50).

Essa passagem reforça cada vez mais o caráter insólito no texto, pois denota o rompimento com o plano da realidade por não poder ser explicada pelas leis da natureza tal como são reconhecidas. As construções subsequentes continuam contribuindo para a inserção num ambiente em que as explicações lógicas para o que é narrado parecem ficar cada vez mais distantes. "Ela ri da divagação que faço. Ainda está acostumado a pensar como os vivos, apieda-se." (LUNARDI, 2002, p. 50). No decorrer do relato do narrador abrese a possibilidade de acreditar na vida após a morte ou crer que os acontecimentos narrados são fruto de delírios. Desse modo, a configuração das passagens subsequentes reforça o que Todorov afirma em Introdução à literatura Fantástica (2004), ao dizer que a instauração do Fantástico e seus desdobramentos são fomentados pela inserção em um mundo conhecido, de ocorrências que não podem ser explicadas com base no que legisla esse mundo familiar, deixando embaralhados os limites entre o real ou sobrenatural.

Revista do SELL, Uberaba/MG (online) - V. 9 n. 2, p. 387-401, jul./dez. - 2020. 
Destarte, não por gratuidade, a fantástica história de Lewis Carroll é revisitada na narrativa lunardiana. Parece-nos intencional as confluências estabelecidas entre as personagens de Alice e o enfermo. Ambos se encontram igualmente perdidos e procurando por ajuda para compreender o processo de atravessamento para diferentes mundos. As visões de um coelho branco em meio ao hospital cumprem a mesma função do coelho de Alice: o transporte para um lugar fantástico, com características peculiares, revelando uma lógica do absurdo. O coelho é o responsável pelo retorno de Alice ao País das Maravilhas. No conto, ele também aparece como uma espécie de anunciador da transposição para outro mundo, aquele sobre o qual não há explicações lógicas. "Novamente o coelho se mexe entre os aventais brancos e sua fala pernóstica soa como um epitáfio. [...] Vigia cada passo de minha trajetória, como se sua presença me obrigasse a continuar em frente" (LUNARDI, 2002, p. 53).

A partir de então predomina na narrativa o caráter insólito. Além do fantasma que aparece para demarcar 0 atravessamento da fronteira entre vida e morte, os acontecimentos seguintes confirmam, pelo que nos conta o narrador-personagem, que a fronteira foi transposta.

Ana C. me explica que eles tentam me levar de volta e pergunta se quero ir. Não agora, me ouço responder. Então venha, ela diz, enquanto me conduz pela mão. Em um instante estamos nas pedras do Arpoador, é dia. [...] Ana C. assente com o olhar, confirmando que acabo de experimentar o primeiro gosto da eternidade. [...] Espio ao redor e testo minha invisibilidade abraçando um menino sem sentir o volume do seu corpo. Meus braços o atravessam e encontram o nada. Na eternidade não há peso nem leveza [...] (LUNARDI, 2002, p. 52).

Diante da certeza de já não ser mais pertencente ao mundo real, o narradorpersonagem confirma seu passamento para o mundo dos mortos, fazendo do leitor um espectador do relato daquele que, agora, vive na eternidade:

Resigno-me com um beijo, expressão mais exata para a minha biografia, e retiro-me, ao lado de Ana C., para assistir à corrida que leva meu corpo por esse corredor que nunca termina (LUNARDI, 2002, p. 54).

Ainda que tenhamos neste conto um passeio pela margem do biográfico, vale ressaltar que não estamos diante de uma biografia dos autores referidos no conto e tampouco de uma autobiografia de Caio Fernando Abreu. Embora os tenhamos como personagens desta ficção que revisita dados biográficos, o que podemos observar em "Ana C." são traços peculiares de uma autora que projeta suas subjetividades a partir das leituras e conhecimento de autores e obras literárias. Ao transitar entre biografia e ficção, Lunardi se reafirma enquanto leitora e escritora que bebe na fonte do insólito para tratar de transcendência literária, sobretudo, e das marcas deixadas pela literatura em seu percurso de vida.

Revista do SELL, Uberaba/MG (online) - V. 9 n. 2, p. 387-401, jul./dez. - 2020. 
SANTOS, F.L.O.

\section{CONSIDERAÇÕES FINAIS}

Diante do exposto, parece-nos ainda mais claro que empreender leitura à produção de uma autora brasileira contemporânea vai além da possibilidade de apreciação estética do texto literário. A densidade semântica da narrativa que o compõe, assim como a complexidade de suas experimentações formais, demarcam seu valor no rol da alta literatura, revelando a potência criativa da escritora e tornando vocal uma categoria que, por muito tempo, não pôde assumir seu lugar de fala para se pronunciar, ser ouvida e apresentar sua arte. Mais especificamente no campo do insólito ou da Literatura Fantástica, escassos são os nomes de brasileiras que possuem notoriedade, desde que o insólito se consolidou no Brasil a partir de 1922, período modernista a partir do qual percebemos obras importantes como as de Guimarães Rosa, Murilo Rubião, Moacyr Scliar, entre outros, e Lygia Fagundes Telles, nome que figura quase que exclusivamente nesse cenário.

A capacidade das autoras de movimentarem-se entre diferentes nuances da literatura parece-nos mais uma conquista das mulheres escritoras que desconstroem o paradigma da escrita melodramática e pouco qualitativa. Torna-se uma forma de emancipação e autonomia de que outras autoras, do final do século $X X$ até a contemporaneidade, têm se valido para marcarem seus lugares e problematizar a forma como lemos e apreendemos o mundo contemporâneo. A esse respeito, Gayatri Spivak retoma os apontamentos de Foucault ao considerar que,

tornar visível o que não é visto pode também significar uma mudança de nível, dirigindo-se a uma camada de material que, até então, não tinha tido pertinência alguma para a história e que não havia sido reconhecida como tendo qualquer valor moral, estético ou histórico (SPIVAK 2010, p. 78).

De alheiamentos a reconhecimentos, as ponderações de Spivak acerca da valoração e da necessidade de conceder visibilidade aos sujeitos que por muito tempo habitaram o terreno da subalternidade, levam-nos a conciliar esta argumentação com a potente observação de Rita Terezinha Schimidt (2009, s/p), ao afirmar que a escrita de autoria feminina concorre para reescrever a cultura, a historiografia, a formação canônica e a crítica literária concedendo maior observância à produção feminina que vem alcançando gradualmente seu espaço de forma mais equilibrada.

\section{REFERÊNCIAS}

BORGES FILHO, O. Espaço e literatura: introdução à topoanálise. In: XI Congresso Internacional da ABRALIC: Tessituras, Interações, Convergências. 13 a 17 de julho de 2008. USP - São Paulo-SP, Brasil. Disponível em: <http://www.abralic.org.br/eventos/cong2008/AnaisOnline/simposios/pdf/067/OZIRIS_FIL HO.pdf>. Acesso em: 20 ago. 2019. 
CHEVALIER, Jean; GHEERBRANT, Alain. Dicionário de Símbolos: (mitos, sonhos, costumes, gestos, formas, figuras, cores, números). Tradução Vera da Costa e Silva et al. 22. ed. Rio de Janeiro: José Olympio, 2008.

Dicionário Digital do Insólito ficcional. Disponível em <http://www.insolitoficcional.uerj.br/site//ffantasma/> Acesso em: 03 de dez. 2019.

FERREIRA, Carlos André. Onde andará Dulce Veiga? A representação da AIDS e do mal-estar do sujeito na obra de Caio Fernando Abreu. 2010. Dissertação (mestrado) Universidade Estadual de Campinas, Instituto de Estudos da Linguagem, Campinas-SP. Disponível em: <http://www.repositorio.unicamp.br/handle/ REPOSIP/270287>. Acesso em: 25 nov. 2019.

GARCIA, Flávio, KHALIL. Marisa, VOLOBUEF, Karin. Vertentes do Insólito Ficcional. ABRALIC, 2011.

LINS, Regina Navarro. Por que há mulheres que se sentem atraídas pelos machões. Disponível em <http://reginanavarro.blogosfera.uol.com.br/2016/08/23/por-quehamulheres-que-se-sentem-atraidas-pelo-machao/>. Acesso em: 24 out. 2019.

LUNARDI, Adriana. Arte e cultura. Entrelinhas. Entrevista com Adriana Lunardi. Disponível em <https://tvcultura.com.br/videos/28857_entrelinhas-adriana-lunardi.html>. Acesso em: 16 out. 2019.

LUNARDI, Adriana. Vésperas. Rio de Janeiro: Rocco, 2002.

SCHMITT, Jean-Claude. Os vivos e os mortos na sociedade medieval. Trad. Maria Lucia Machado. São Paulo: Companhia das Letras, 1999.

SHIMIDT, Rita Terezinha. Na literatura, mulheres que reescrevem a nação. In HOLANDA, Heloísa Buarque (org.). Pensamento feminista brasileiro: formação e contexto. Rio de Janeiro: Bazar do Tempo, 2019.

SILVA, Vera Lopes. A escrita de si na leitura do outro - a autoficção e a memória no conto "Ana C.", de Adriana Lunardi. Em Tese. Volume 24. n. 01. Janeiro a abril de 2018. ISSN: 1982-0739. Disponível em <http://www.periodicos.letras.ufmg.br/ index.php/emtese/article/view/13341>. Acesso em: 13 dez.2019.

SPIVAK, Gayatri Chakravorty. Pode o subalterno falar? Tradução Sandra Regina Goulart Almeida, Marcos Pereira Feitosa, André Pereira Feitosa. Belo Horizonte: Editora UFMG, 2010.

TELLES, Norma. Autor+a. In: JOBIM, Jose Luis (Org.). Palavras da crítica. Tendências e Conceitos no Estudo da Literatura. Rio de Janeiro: Imago Ed., 1992, p. 45-63.

VASCONCELLOS. Odisseia. Adaptação, apresentação e notas de Paulo Sérgio Vasconcellos. São Paulo - SP. Sol Editora. 2019.

WOOLF, Virginia. Um teto todo seu. Tradução Bia Nunes de Sousa, Glauco Mattoso. 1. ed. São Paulo. Tordesilhas, 2014. 
Como citar este artigo (ABNT)

SANTOS, F.L.O. Ana C. Biografias ficcionalizadas pelas sendas do insólito SELL, Uberaba, MG, v. X, n. X, p. XXX-XXX, 2019. Disponível em: <inserir link de acesso>. Acesso em: inserir dia, mês e ano de acesso. DOI: inserir link do DOI.

Como citar este artigo (APA)

Santos, F.L.O. Ana C. Biografias ficcionalizadas pelas sendas do insólito. SELL, X (X), XXXXXX. Recuperado em: inserir dia, mês e ano de acesso de inserir link de acesso. DOI: inserir link do DOI. 